\section{Endoscopic fenestration of esophageal duplication cysts}

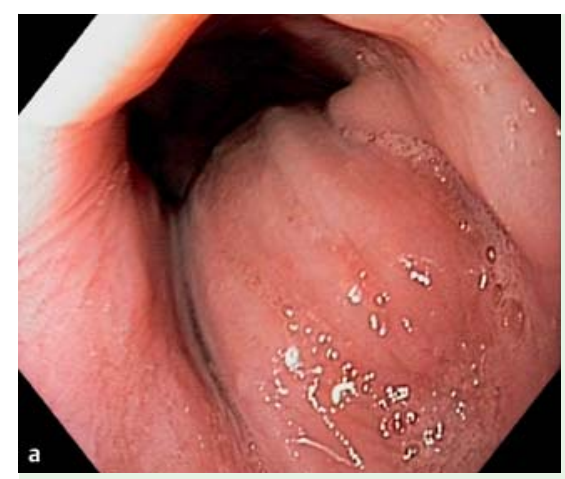

Fig. 1 a Protruding submucosal lesion in a lower third of the esophagus seen at the index upper endoscopy in a middle-aged patient with recent dysphagia. b Protruding lesion in a lower third of the esophagus seen on the esophagogram.
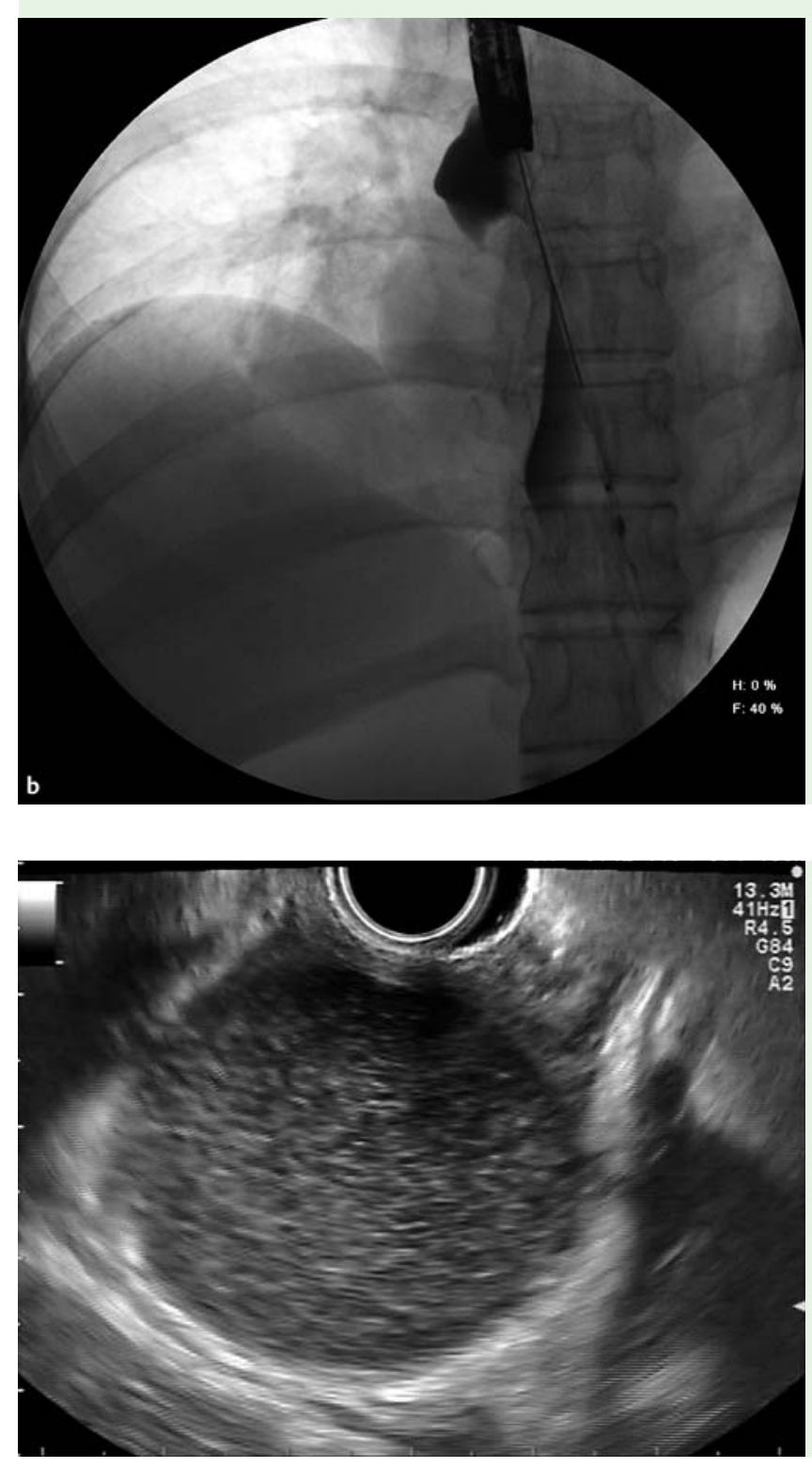

The esophageal duplication cyst is an unusual congenital disorder of the foregut, accounting for $10 \%-15 \%$ of duplications of all foregut cysts [1]. Up to $80 \%$ of esophageal duplication cysts are diagnosed in childhood and symptomatic cysts in adults are very rare [2]. Although surgical excision provides definitive treatment, we report two patients with esophageal duplication cysts successfully treated endoscopically.

Both patients (a 51-year-old man and a 32-year-old woman) were admitted to our hospital because of recent development of dysphagia for solid food. Esophagogastroduodenoscopy (EGD) and esophagography demonstrated a protruding submucosal lesion in the lower third of the esophagus ( $\bullet$ Fig.1). Endoscopic ultrasound demonstrated a hypoechogenic cystic lesion measuring $45 \mathrm{~mm}$ and $65 \mathrm{~mm}$ in the two patients, respectively ( $\bullet$ Fig.2), surrounded by a multilayered wall, consistent with the diagnosis of esophageal duplication cyst. Based on our previous experience of endoscopic treatment of duodenal duplication cysts [3], we proposed using the same approach, and informed consent was obtained for both patients. After making the initial incision with a needle-knife (Olympus, Tokyo, Japan), the anterior wall of the duplication cyst was fenestrated with the ITknife (Olympus, Tokyo, Japan), resulting in the complete opening of the cystic cavity into the esophageal lumen ( $\bullet$ Fig.3). The lateral margins were then clipped to close any gaps and to prevent delayed bleeding. A follow-up EGD demonstrated epithelialization of the posterior wall of the esophageal duplication cyst ( $\bullet$ Fig.4).

Small, pedunculated esophageal duplication cysts, located superficially, can be completely resected with a standard polypectomy snare [4]. However, for large duplication cysts buried deeper into esophageal wall, we propose careful fenestration with the IT-knife to avoid deep injury once the cyst has been emptied. Resection of the entire length of the cyst wall is essential, since partial incision can lead to recurrence of symptoms [5]. We believe that this report provides additional evidence of the safe and effective endoscopic treatment of esophageal duplication cysts.

Endoscopy_UCTN_Code_TTT_1AO_2AN

Competing interests: None 

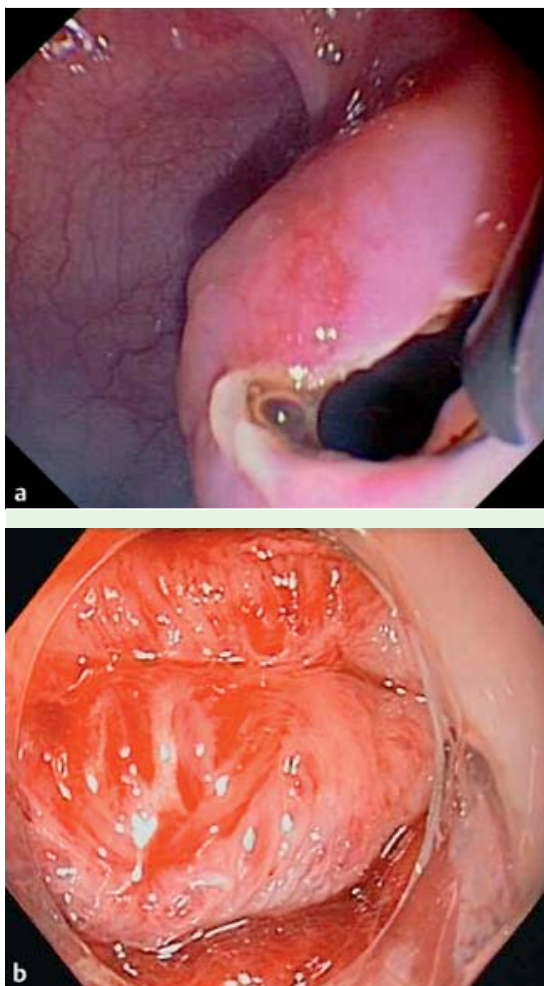

Fig. 3 a Incision of the esophageal duplication cyst with the IT-Knife. b Complete opening (fenestration) of the cystic cavity into the esophageal lumen.

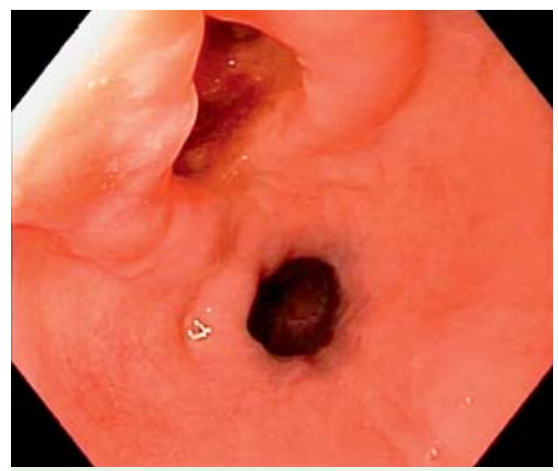

Fig. 4 Follow-up esophagogastroduodenoscopy (EGD) showing epithelialization of the esophageal duplication cyst.

\section{H. Ivekovic ${ }^{1}$, A. Jouret-Mourin ${ }^{2}$, P. H. Deprez ${ }^{3}$}

${ }^{1}$ Department of Gastroenterology and Hepatology, University Hospital Centre Zagreb, Kispaticeva, Zagreb, Croatia

2 Department of Pathology, Cliniques universitaires Saint-Luc, Avenue Hippocrate, Brussels, Belgium

${ }^{3}$ Department of Hepato-Gastroenterology, Cliniques universitaires Saint-Luc, Avenue Hippocrate, Brussels, Belgium

\section{Acknowledgment \\ $\nabla$}

Hrvoje Ivekovic is a recipient of the European Society of Gastrointestinal Endoscopy Travel Grant-Module 2.

\section{References}

1 Anderson MC, Silberman WW, Shields TW. Duplications of the alimentary tract in the adult. Arch Surg 1962; 85: 94-108

2 Gross RE, Holcomb GW, Farber S. Duplications of the alimentary tract. Pediatrics 1952; 9: $448-468$

3 Antaki F, Tringali A, Deprez P et al. A case series of symptomatic intraluminal duodenal duplication cysts: presentation, endoscopic therapy, and long-term outcome (with video). Gastrointest Endosc 2008; 67 (Suppl. 01): $163-168$

4 Joyce AM, Zhang PJ, Kochman ML. Complete endoscopic resection of an esophageal duplication cyst (with video). Gastrointest Endosc 2006; 64 (Suppl. 02): 288-289

5 Will U, Meyer F, Bosseckert H. Successful endoscopic treatment of an esophageal duplication cyst. Scand J Gastroenterol 2005; 40 : 995-999

\section{Bibliography}

Dol http://dx.doi.org/

10.1055/s-0032-1310144

Endoscopy 2012; 44: E404-E405

(c) Georg Thieme Verlag KG

Stuttgart · New York

ISSN 0013-726X

\section{Corresponding author}

\section{Professor P. H. Deprez}

Department of Hepato-Gastroenterology

Cliniques universitaires Saint-Luc

Université Catholique de Louvain

Avenue Hippocrate 10

B-1200 Brussels

Belgium

Fax: +32-(0)2-7648927

pdeprez@uclouvain.be 